\title{
Qualidade microbiológica da marcela (Achyrocline satureioides (LAM.) DC.) comercializada por vendedores ambulantes
}

\author{
Microbiological quality of marcela (Achyrocline satureioides (LAM.) DC.) traded by street
} vendors

\author{
M. C. Martins'; E. D. Stolz²; M. G. Gadea ${ }^{2}$; T. R. Moresco ${ }^{2 *}$ \\ ${ }^{1}$ Departamento de Zootecnia e Ciências Biológicas, Universidade Federal de Santa Maria, 98300-000, Palmeira das \\ Missões, Rio Grande do Sul, Brasil \\ ${ }_{2}^{2}$ Departamento de Ciências Saúde, Laboratório de Microbiologia, Universidade Federal de Santa Maria, 98300-000, \\ Palmeira das Missões, Rio Grande do Sul, Brasil \\ *terimarm@hotmail.com
}

(Recebido em 24 de junho de 2019; aceito em 26 de setembro de 2019)

\begin{abstract}
O Brasil possui diversidade biológica e cultural que colabora para que as plantas medicinais sejam utilizadas como uma alternativa ao uso de medicamentos. Por serem naturais e menos onerosas, seu consumo tem aumentado, porém a falta de fiscalização na sua comercialização põe em discussão sua qualidade. Esse trabalho visa analisar a qualidade microbiológica de amostras de Achyrocline satureioides (LAM.) DC., popularmente conhecida por marcela, comercializadas por feirantes em cidades do Rio Grande do Sul (RS) Brasil. Foram analisadas bactérias mesófilas, fungos, coliformes totais e termotolerantes, Staphylococcus coagulase negativa e positiva e Escherichia coli. Todas as análises seguiram a metodologia descrita no Manual de Métodos de Análise Microbiológica de Alimentos e Água. Os resultados indicam que as amostras estão adequadas para consumo conforme preconiza a legislação brasileira. A contaminação por bactérias mesófilas aeróbias apresentou variação de $2,6 \times 10^{3}$ a $1,2 \times 10^{6}$ UFC e por fungos foi de $1,8 \times 10^{3}$ a $4,2 \times 10^{4}$ UFC. Quatro amostras apresentaram contagem para coliformes totais, duas para coliformes termotolerantes e somente em uma amostra foi detectada E. coli. Staphylococcus coagulase positiva não foi detectado. Em vista dos argumentos apresentados conclui-se que a marcela comercializada por feirantes e vendedores ambulantes de cidades do RS não apresenta riscos microbiológicos à população, pois atendem às especificações e critérios compreendidos pela legislação brasileira para microrganismos indicadores de contaminação ambiental e por manipulação.
\end{abstract}

Palavras-chave: planta medicinal, contaminação microbiológica, qualidade higiênico-sanitária.

Brazil has a great biological and cultural diversity that collaborates so that medicinal plants are an alternative to the use of medicines. Due to its lower cost and because it is natural, its consumption has increased, but the lack of supervision in the commercialization puts in question its quality. This work aims to analyze the microbiological quality of marcela, Achyrocline satureioides (LAM.) DC. commercialized by vendors in towns of Rio Grande do Sul (RS). It was performed analyzes of mesophilic bacteria, fungi, total and thermotolerant coliforms, positive and negative coagulase Staphylococcus and Escherichia coli. All analyzes followed the methodology described in the Manual of Methods of Microbiological Analysis of Food and Water. The results indicate that the samples are suitable for consumption as recommended by Brazilian legislation. Contamination by aerobic mesophilic bacteria showed a variation of $2.6 \times 10^{3}$ and $1.2 \times 10^{6} \mathrm{CFU} / \mathrm{g}$, and fungi $1.8 \times 10^{3}$ to $4.2 \times 10^{4} \mathrm{CFU} / \mathrm{g}$. Only four samples showed counts for total coliforms, two for thermotolerant coliforms and only one sample detected E. coli. Staphylococcus coagulase positive was not detected. Therefore, it is concluded that the marcela marketed by market stalls and street vendors of RS towns does not present microbiological risks to the population, considering the specifications and criteria included in the Brazilian legislation for microorganisms that are indicators of environmental contamination and manipulation.

Key words: medicinal plant, microbiological contamination, hygienic-sanitary quality. 


\section{INTRODUÇÃO}

Apesar de todos os avanços biotecnológicos para produção de medicamentos sintéticos, o uso de fitoterápicos tem sido estimulado pelos órgãos públicos. Esse aumento se deve, principalmente, ao alto custo dos medicamentos sintéticos, efeitos adversos, bem como, ao interesse na preservação da cultura brasileira. No Brasil, os produtos consumidos como plantas medicinais devem atender ao disposto na RDC 10/2010 [1], que considera plantas medicinais como

plantas ou suas partes, que contenham as substâncias, ou classes de substâncias, responsáveis pela ação terapêutica, após processos de coleta ou colheita, estabilização e secagem, íntegras, rasuradas, trituradas ou pulverizadas.

Segundo esse documento, plantas medicinais que passam por processo extrativo a quente (preparados por infusão e decocção) necessitam atender a um rigoroso controle de qualidade para não representarem risco à saúde pública. Os parâmetros microbiológicos preconizados são bactérias aeróbicas: máximo de $10^{7} \mathrm{UFC} / \mathrm{g}$ (Unidades Formadoras de Colônia por grama); fungos: máximo de $10^{4} \mathrm{UFC/g}$; Escherichia coli: máximo de $10^{2} \mathrm{UFC/g}$; outras enterobactérias: máximo de $10^{4}$ $\mathrm{UFC/g}$; ausência de salmonela e de aflatoxinas [1].

Sabe-se que a eficácia e segurança terapêutica de espécies vegetais dependem da sua qualidade, exigindo obediência às condições ideais de cultura, colheita, secagem, estabilização, manufatura, conservação e armazenamento [2]. Entretanto, o aumento da procura por plantas medicinais frente à oferta insuficiente pode estar associado a uma queda de qualidade [3]. Em geral, o consumo de plantas medicinais pela população é abastecido pelas feiras populares, sob condições higiênicas indesejáveis do ponto de vista médico-sanitário [4].

Considerando o modo de comercialização citado acima, a possibilidade de contaminações microbiológicas em plantas medicinais deve ser atentamente observada [5]. Microrganismos potencialmente patogênicos podem ser encontrados nos vegetais, como por exemplo a Escherichia coli; esse compreende um dos mais prevalentes microrganismos de origem ambiental [6], cujo habitat natural é o trato intestinal de animais de sangue quente [7]. Essa bactéria representa um dos principais agentes de infecções intestinais [8]. Outro microrganismo é Staphylococcus aureus, bactéria conhecida pelo envolvimento em casos ou surtos de intoxicação alimentar [9], apresenta toxinas altamente resistentes, suportando tratamentos térmicos tão severos como a esterilização de alimentos de baixa acidez [7]. Sendo as mãos e as fossa nasais os principais veículos de contaminação desse microrganismo [10].

Muitos fungos são encontrados em alimentos secos armazenados, como os chás. Esses microrganismos atuam na degradação de substâncias, alterando o teor de princípio ativo, fazem com que os produtos percam seu valor terapêutico. Também causam doenças alergênicas [11], cuja contaminação representa um sério problema de saúde para humanos e animais [12]. Além disso, podem produzir micotoxinas termoestáveis, resistindo a tratamentos térmicos ou processos de desidratação que são suficientes para destruir o micélio vegetativo dos fungos que as produziram [13].

Dentre as plantas utilizadas como terapêuticas no sul do Brasil, destaca-se a Achyrocline satureioides (LAM.) DC, pertencente à família Asteraceae, conhecida como marcela ou macela [14]. É uma planta nativa de campos de áreas abertas do Sul e Sudeste do Brasil e cresce espontaneamente em pastagens e beiras de estradas, sendo considerada pelos agricultores como "planta daninha" [15]. No Rio Grande do Sul, a Lei n ${ }^{\circ} 11.858$, de dezembro de 2002 [16] instituiu a marcela como Planta Medicinal Símbolo do Estado e consagrou seu uso popular.

Na medicina tradicional, suas inflorescências têm sido utilizadas para o tratamento de problemas do trato digestivo, má digestão e cólicas intestinais, como sedativo leve e como anti-inflamatórios $[1,17,18]$. O presente trabalho objetivou analisar a qualidade microbiológica de Achyrocline satureioides (LAM.) DC., comercializada em cidades do Rio Grande do Sul, para colaborar com o entendimento sobre seu potencial risco microbiológico. 


\section{MATERIAL E MÉTODOS}

\subsection{Material vegetal}

Foram coletadas 12 amostras de marcela entre os meses de outubro de 2016 e junho de 2017, em diferentes cidades do Rio Grande do Sul, Brasil (Figura 1): três amostras em Palmeira das Missões, duas amostras em Santa Maria e uma amostra em cada uma das demais cidades. A escolha dos locais deu-se de forma aleatória, a fim de contemplar diferentes regiões do estado. As amostras foram coletadas diretamente em seus pontos de venda (feiras populares ou junto a vendedores ambulantes), colocadas em sacos plásticos estéreis herméticos, identificadas e transportadas até o laboratório de microbiologia da Universidade Federal de Santa Maria (UFSM)/Palmeira das Missões para serem processadas. Descartaram-se outras partes da planta que não fossem as inflorescências.
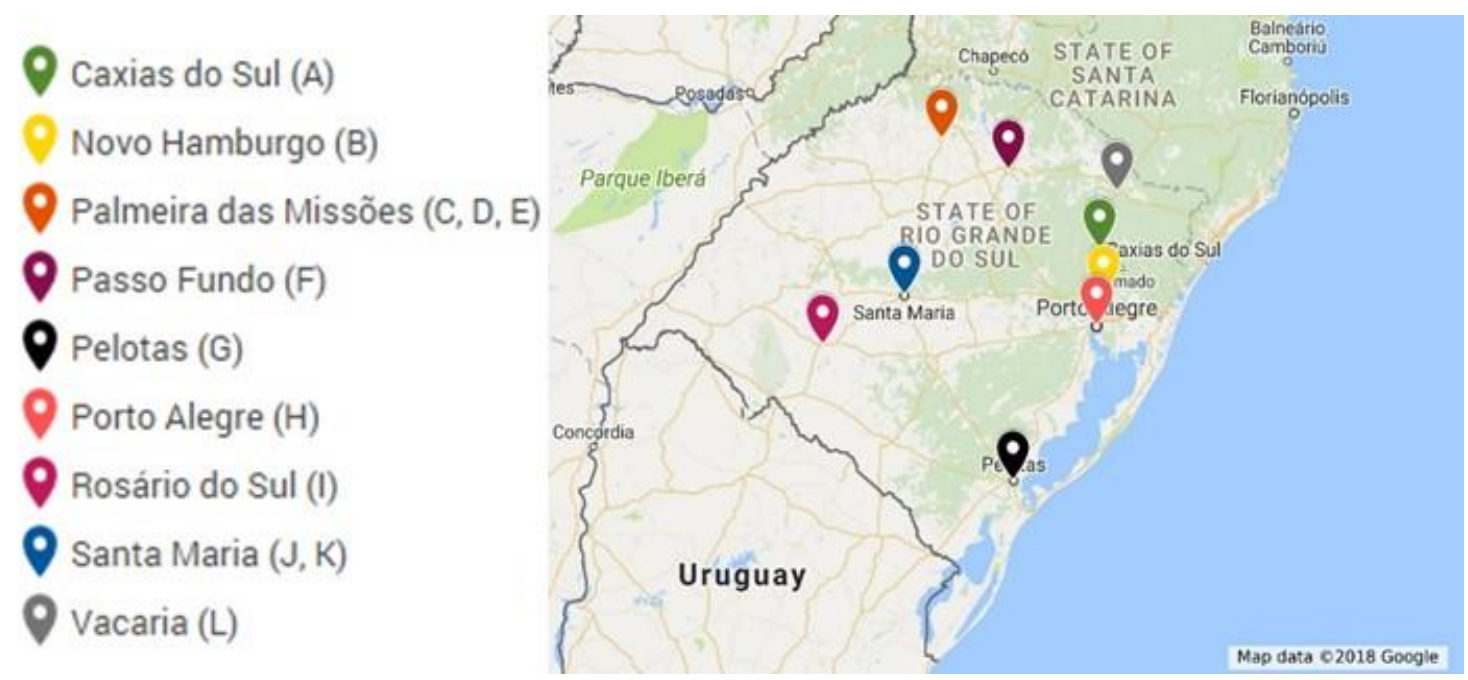

Figura 1: Locais de coleta das amostras de marcela avaliadas no Rio Grande do Sul. Fonte: adaptado de Google 2018.

\subsection{Análises microbiológicas}

Realizaram-se análises para contagem de bactérias totais aeróbias mesófilas, fungos, coliformes totais e termotolerantes e Staphylococcus. Os procedimentos ocorreram de acordo com o Manual de Métodos de Análise Microbiológica de Alimentos e Água [7], em triplicata. Foram pesadas 10 $\mathrm{g}$ de inflorescência de cada amostra para diluição em $90 \mathrm{ml}$ de água peptonada tamponada e, em sacos estéreis, as amostras foram homogeneizadas em stomacher a 370 GPM (golpes por minuto) por 2 minutos. A partir dessa diluição $\left(10^{-1}\right)$ foram preparadas as demais diluições, $\left(10^{-2}\right.$ e $\left.10^{-3}\right)$, para proceder as análises descritas a seguir, todas em triplicata. Após o tempo de incubação para cada teste, escolheu-se a placa que continha entre 30 e 300 UFC, feita a contagem e calculada a quantidade de aeróbios mesófilos por grama do vegetal.

\subsection{Contagem total de aeróbios mesófilos}

Empregou-se Ágar Padrão para Contagem (PCA) para proceder à inoculação por plaqueamento em superfície, utilizando $0,1 \mathrm{ml}$ de cada diluição. Após $48 \mathrm{~h}$ de incubação a $35^{\circ} \mathrm{C} \pm 1^{\circ} \mathrm{C}$, foi feita a contagem das UFC e calculada a quantidade de aeróbios mesófilos por grama do vegetal.

\subsection{Contagem de fungos}

Utilizou-se Ágar Batata Dextrose (BDA) com Ácido Tartárico a 10\%, a fim de realizar a inoculação por plaqueamento em superfície, utilizando $0,1 \mathrm{ml}$ de cada diluição. Após 5 dias de 
incubação a $22-25^{\circ} \mathrm{C} \pm 1^{\circ} \mathrm{C}$, procedeu-se à contagem das UFC e, ao cálculo da quantidade de fungos por grama do vegetal.

\subsection{Contagem de coliformes}

Na contagem de coliformes aplicou-se a técnica do Número Mais Provável (NMP). As diluições foram inoculadas em uma série de três tubos de Caldo Lauril Sulfato Triptose (LST), adicionando $1 \mathrm{ml}$ da diluição por tubo com $9 \mathrm{ml}$ de LST. Após incubação por $48 \mathrm{~h}$, a $35^{\circ} \mathrm{C} \pm 1^{\circ} \mathrm{C}$, os tubos que apresentaram produção de gás foram transferidos, com alça calibrada $(10 \mu \mathrm{L})$, para tubos com Caldo Verde Brilhante Bile 2\% (VB) e outra para tubos com Caldo E. coli (EC). Tubos VB foram incubados a $35^{\circ} \mathrm{C}$, por 24 a $48 \mathrm{~h}$, e tubos $\mathrm{EC}$ foram incubados por 24 a $48 \mathrm{~h}$, em banho-maria a $45,5^{\circ} \mathrm{C}$. Anotou-se o número dos tubos de $\mathrm{VB}$ e EC com crescimento e produção de gás para determinar o NMP de coliformes totais e coliformes termotolerantes, respectivamente. De cada tudo de EC positivo, transferiu-se uma alçada da cultura em placas de Ágar Levine Eosina Azul de Metileno (EMB-L) através de estrias de esgotamento. Incubaram-se as placas a $35 \pm 1^{\circ} \mathrm{C}$, por $24 \pm$ $2 \mathrm{~h}$. As colônias típicas de E. coli, quando existentes, foram transferidas para tubos de PCA inclinados e incubadas a $35 \pm 1^{\circ} \mathrm{C}$ por $24 \pm 2 \mathrm{~h}$. A partir dessas colônias, desenvolveu-se análise bioquímica, mediante meios de cultura (Tríplice Açúcar Ferro - TSI, Motilidade Indol Ornitina MIO, CITRATO, INDOL, UREASE e LISINA) para confirmação da bactéria.

\subsection{Contagem de Staphylococcus}

A inoculação se deu por plaqueamento em superfície, utilizando $0,1 \mathrm{ml}$ de cada diluição em placas com Ágar Manitol. Após incubação a $37^{\circ} \mathrm{C} \pm 1^{\circ} \mathrm{C}$, por $45 \mathrm{~h}$, as colônias típicas foram transferidas para os tubos com $3 \mathrm{ml}$ de Caldo Infusão Cérebro Coração (BHI). Nesses tubos de BHI, após $18 \mathrm{~h}$ de incubação a $35-37^{\circ} \mathrm{C}$, foi realizado o teste da coagulase, utilizando $0,2 \mathrm{ml} \mathrm{do}$ Caldo BHI para 0,5 ml de Plasma de Coelho com EDTA.

\subsection{Análise dos dados}

Para a análise descritiva dos dados, empregou-se o software GraphPad Prism 5 com o objetivo de calcular a média e o desvio padrão das triplicatas.

\section{RESULTADOS E DISCUSSÃO}

Os resultados indicam que das 12 amostras de marcela comercializadas em feiras livres de diferentes cidades do Rio Grande do Sul, quatro apresentaram contagem de fungos no limite máximo permitido pela RDC 10/2010 [1]. Embora a quantidade de fungos encontrada em todas as amostras tenha sido menor do que a quantidade de bactérias, a tolerância legal à presença deles é mais baixa: máximo de $10^{4}$ UFC de fungos por grama de chá [1]. A contagem de fungos nessa pesquisa apresentou variação de $1,8 \times 10^{3}$ até $4,2 \times 10^{4} \mathrm{UFC} / \mathrm{g}$ (Figura 2.1).

Todas as amostras apresentaram altas contagens bacterianas, entretanto permaneceram dentro dos limites preconizados pela legislação. A contagem de aeróbios mesófilos, apesar de não ser um indicador higiênico-sanitário porque não está diretamente relacionado à presença de patógenos e toxinas, é útil na avaliação da qualidade do armazenamento, da sanitização [7] e de procedimentos inadequados de colheita e pós-colheita [11]. Nas amostras avaliadas, a contagem apresentou

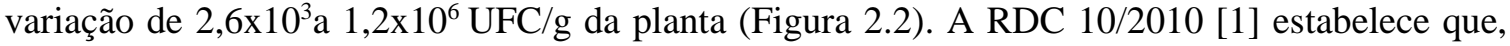
para plantas medicinais que passarão por processo extrativo a quente, o limite máximo é de $10^{7}$ UFC/g de bactérias aeróbias. 
2.1 Fungos

(UFC/g de marcela)

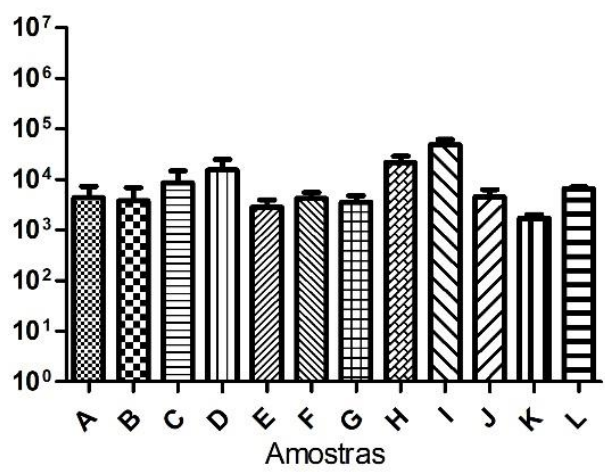

2.2 Mesófilos

(UFC/g de marcela)

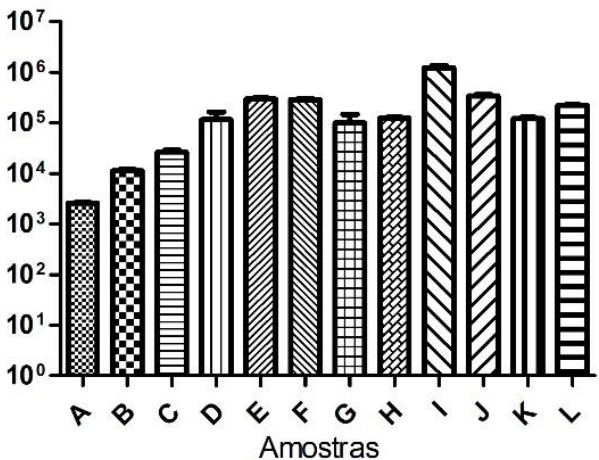

Figura 2. 2.1: Contagem de fungos presentes nas amostras de marcela avaliadas. 2.2: Contagem de bactérias mesófilas aeróbias presentes nas amostras de marcela avaliadas. Resultados expressos em média e desvio padrão. Cada coluna representa um ponto de coleta, sendo: Caxias do Sul (A), Novo Hamburgo (B), Palmeira das Missões (C, D, E), Passo Fundo (F), Pelotas $(G)$, Porto Alegre (H), Rosário do Sul (I), Santa Maria (J, K), Vacaria (L). Fonte: Os autores.

Em um estudo com amostras de marcela avaliadas em duas cidades do Paraná, encontraram-se

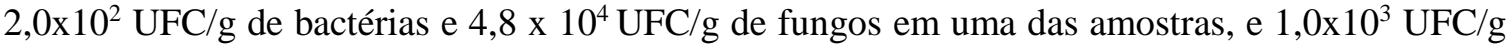
de bactérias e $1,0 \times 10^{5} \mathrm{UFC} / \mathrm{g}$ de fungos em outra [3]. Ou seja, diferentemente desse estudo, a quantidade de fungos foi maior do que a quantidade de bactérias.

A partir desses resultados, podemos inferir que o mecanismo de colheita e armazenamento, aplicado às amostras, apresentou eficácia quanto à conservação já que ocorreram baixas quantidades de microrganismos viáveis no momento da comercialização. Entretanto, como já está bem descrito pela literatura, dependendo das condições de armazenamento, os fungos, mesmo que em pequena quantidade, podem se reproduzir, produzir micotoxinas, ou mesmo enzimas que aceleram a deterioração do produto [19]. A detecção de micotoxinas nos alimentos é o primeiro passo para a implementação de programas para adoção de medidas preventivas para a redução do problema [12]. O melhor método para controlar a contaminação de alimentos por micotoxinas é prevenir o crescimento de fungos através da adoção de boas práticas de produção de alimentos [13].

A presença de coliformes é o melhor indicativo de deficiência na higiene durante o preparo dos alimentos [20]. Das 12 amostras avaliadas, quatro tiveram resultados positivos para coliformes totais e em duas foram detectadas coliformes termotolerantes. Em uma única amostra identificouse E. coli (Tabela 1). Embora não tenha sido quantificada presume-se que a quantidade dessa bactéria não ultrapasse o número de coliformes termotolerantes, já que a identificação é feita a partir desse teste. Assim infere-se que a quantidade de E. coli na amostra esteja abaixo do limite permitido pela resolução, já que a normativa estabelece um limite máximo de $10^{2} \mathrm{UFC/g}$ de E. coli, $10^{4} \mathrm{UFC} / \mathrm{g}$ de outras enterobactérias e ausência de Salmonella [1].

Tabela 1: Contagem de coliformes totais, coliformes termotolerantes e Escherichia coli em amostras de Achyrocline satureioides (LAM.) DC.

\begin{tabular}{cccc}
\hline & \multicolumn{3}{c}{ Coliformes } \\
\cline { 2 - 4 } Amostra & Totais (NMP/g) & $\begin{array}{c}\text { Termotolerantes } \\
\text { (NMP/g) }\end{array}$ & E. coli \\
\hline A & 75 & 460 & Ausente \\
C & 150 & Ausente & Ausente \\
G & 28 & Ausente & Ausente \\
J & 240 & 3 & Presente \\
\hline
\end{tabular}

Trabalhos que abordam a presença de coliformes totais apresentam valores muito diferentes. Amostras de Pimpinella anisum L. comercializadas em lojas de produtos naturais, manifestaram 
variação de < 3,0 a $1100 \mathrm{NMP} / \mathrm{g}$ [21]. Na análise de 16 amostras de chá de Cymbopogon citratus (D.C.) Stapf, de quatro marcas comercializadas em supermercados, os pesquisadores verificaram a presença de coliformes totais em 50\% das amostras, nas quais os valores variaram de 9 a $>1100$ NMP [11]. As diferenças apresentadas nos valores demonstraram que existem variações nas condições higiênico-sanitárias de cada amostra.

Coliformes termotolerantes também foram encontrados em especiarias comercializadas em feira livre, cuja contagem variou de 0,4 a $240 \mathrm{NMP} / \mathrm{g}$ [19]. A presença desses microrganismos e de $E$. coli indicam contaminação fecal e, portanto, condições higiênico-sanitárias insatisfatórias [22], revelando problemas no tratamento e/ou na manipulação [23]. A E. coli pode apresentar diversos mecanismos de patogenicidade (toxinas, adesinas, invasibilidade), causando várias doenças no homem [23], tais como diarreia aquosa, colite hemorrágica, síndrome hemolítica-urêmica e púrpura trombocitopênica trombótica [24].

No Sul do Brasil, tradicionalmente, a marcela deve ser colhida na Sexta-Feira Santa, antes do sol nascer, pois acredita-se que assim traga mais eficiência ao chá, entretanto ela é comercializada ao longo de todo o ano e para isso ela precisa ser desidratada [26]. O processo de desidratação pode ser o responsável pela diminuição na carga microbiana, visto que baixa atividade de água impede a proliferação de microrganismos, o que já foi observado com o coentro que, in natura, apresentou $23 \mathrm{NMP} / \mathrm{g}$ de coliformes e, após a desidratação, houve redução de contagem para < $3 \mathrm{NMP} / \mathrm{g}$ [25].

Com relação à Staphylococcus aureus, a Farmacopeia Brasileira [27] estabelece ausência do microrganismo em $1 \mathrm{~g}$ em preparação para uso oral contendo matéria-prima de origem natural. Nesse trabalho, a análise microbiológica foi realizada com o produto vegetal e não com o chá preparado, mas ainda assim Staphylococcus coagulase positiva não foi encontrada em nenhuma dessas amostras avaliadas. Zaroni et al. (2004) [3], avaliando amostras de marcela, também não detectaram presença de Staphylococcus aureus. A intoxicação causada pelas toxinas produzidas por Staphyococcus aureus é a causa mais frequente de surtos de doenças microbianas transmitidas por alimentos em alguns países [28]. Tal intoxicação é provocada pela ingestão de toxinas (resistentes à cocção e às enzimas proteolíticas) pré-formadas no alimento, quando ocorre a multiplicação das células [7].

No entanto, 11 das 12 amostras continham número considerável de Staphylococcus coagulasenegativa (Figura 3). A produção de enterotoxinas por Staphylococcus coagulase negativa foi relatada por vários estudos realizados sob condições de laboratório [28]. Os Staphylococcus coagulase-negativa representam o maior componente da microbiota cutânea e recentemente emergiram como capazes de causar várias infecções humanas, que frequentemente conduzem a uma infecção persistente [29].

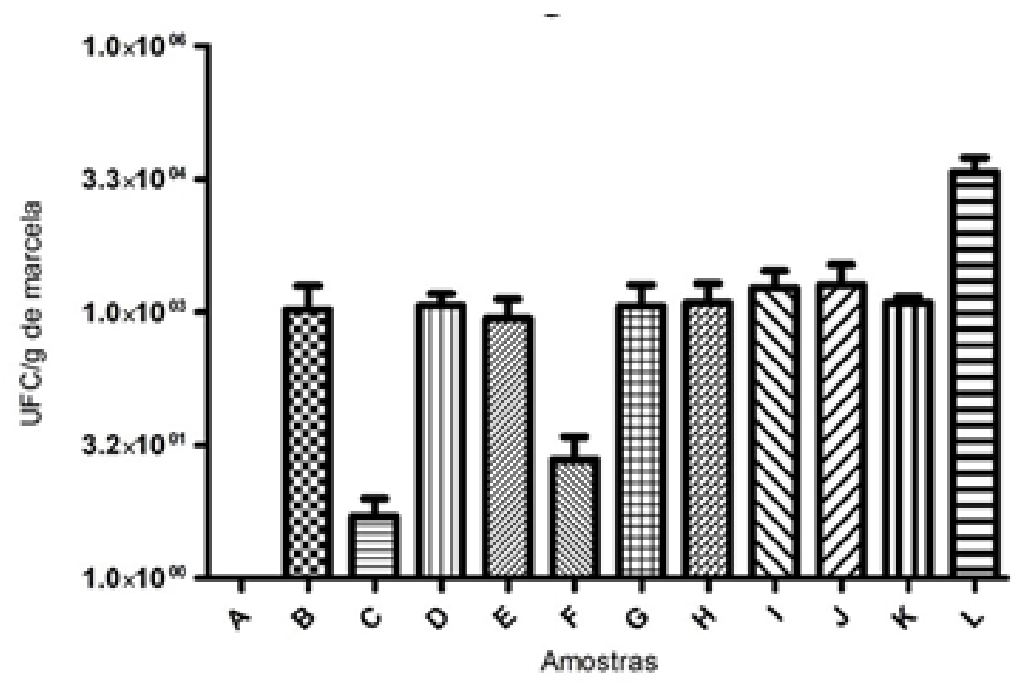

Figura 3: Contagem de Staphylococcus coagulase-negativa presentes nas amostras de marcela avaliadas. Resultados expressos em média e desvio padrão. Cada coluna representa um ponto de coleta, sendo: Caxias do Sul (A), Novo Hamburgo (B), Palmeira das Missões (C, D, E), Passo Fundo (F), Pelotas $(G)$, Porto Alegre (H), Rosário do Sul (I), Santa Maria (J, K), Vacaria (L). 
Avaliando a qualidade microbiológica de especiarias desidratadas, Furlaneto e Mendes (2004) [19] afirmam que a contaminação por microrganismos ou infestação de insetos podem reduzir a qualidade do alimento devido à perda de óleos essenciais voláteis. O conteúdo de princípios ativos de cada espécie vegetal varia com a estação de colheita, armazenamento e condições de secagem [30]. Em sua composição, a marcela apresenta compostos fenólicos (flavonóis, flavononas e derivados do ácido cafeico), aos quais se atribui atividade antioxidante [31] e de onde decorre o interesse da avaliação de sua atividade farmacológica e de sua estabilidade química em produtos destinados ao uso terapêutico [32]. López et al. (1996) [30] encontraram diferenças no teor dos derivados de ácido cafeico de amostras comerciais de marcela, atribuindo o resultado ao fato do material vegetal ter sido coletado em diferentes épocas do ano e / ou a má conservação do mesmo.

A baixa contaminação da marcela pode ser explicada pelo fato de algumas plantas conterem barreiras naturais e substâncias antimicrobianas, impedindo seu crescimento ou mesmo mantendo a carga microbiana baixa, mesmo após sua manipulação ou com armazenamento inadequado. Avaliando a atividade antimicrobiana pela técnica da difusão em disco dos extratos metanólicos brutos da marcela, Golçalves (2010) [33] constatou ação da inflorescência para Staphyloccocus aureus e Bacillus cereus. Os resultados indicam certa especificidade de ação destes extratos, o que é interessante para uma droga antimicrobiana, pois confere certa seletividade [33].

Verter água fervente sobre a planta medicinal, tapar o recipiente para que não se percam as essências voláteis e aguardar alguns minutos, segundo Verdi et al. (2013) [34], pode reduzir ainda mais a carga microbiana, visto que a água fervente auxilia na eliminação dos microrganismos. No entanto, os autores ainda mencionam que isto depende das condições empregadas no processo de infusão. Além disso, as toxinas, fúngicas ou bacterianas, estáveis nos processos que envolvem altas temperaturas, podem permanecer ativas após a infusão.

Outro risco a ser considerado, diz respeito ao comércio informal dos chás. Esses produtos são utilizados em larga escala e são consumidos após um prazo variável de estocagem [19]. Para Souza e Maciel (2010) [35], a estocagem, bem como condições de coleta, manipulação e secagem, são fatores importantes a serem considerados no controle de produtos naturais por possibilitarem altos níveis de contaminação microbiana, por vezes patogênicas.

Assim sendo, a contaminação da marcela, bem como de outras espécies vegetais, pode ser reduzida pelo desenvolvimento de boas práticas de colheita, de armazenamento e de manipulação. Ressalta-se que, embora nas 12 amostras avaliadas, a qualidade microbiológica se manteve dentro dos padrões preconizado pela RDC $\mathrm{N}^{\circ} 10 / 2010$, a presença de coliformes indicou contaminação oriunda da manipulação e pode representar risco à saúde.

\section{CONCLUSÃO}

Em vista dos argumentos apresentados, conclui-se que as amostras de marcela analisadas e comercializadas por feirantes e vendedores ambulantes de cidades do RS não apresentam riscos microbiológicos à população, atendendo às especificações e critérios compreendidos pela legislação brasileira para microrganismos indicadores de contaminação ambiental e por manipulação.

\section{REFERÊNCIAS BIBLIOGRÁFICAS}

1. BRASIL. Resolução RDC no 10 , de 9 de março de 2010. Dispõe sobre a notificação de drogas vegetais junto à Agência Nacional de Vigilância Sanitária (ANVISA) e dá outras providências. Disponível em: http://bvsms.saude.gov.br. Acesso em: 03 dez. 2017.

2. Amaral FMM, Coutinho DF, Ribeiro MNS, Oliveira MA. Avaliação da qualidade de drogas vegetais comercializadas em São Luís/Maranhão. Rev Bras Farmacogn. 2003;13:27-30, doi: 10.1590/S0102695X2003000300011.

3. Zaroni M, Pontarolo R, Abrahão WSM, Fávero MLD, Correa Júnior C, Stremel DP. Qualidade microbiológica das plantas medicinais produzidas no Estado do Paraná. Rev Bras Farmacogn. 2004 Jan;14(1):29-39.

4. Rocha FAG, Medeiros FGM, Silva JLA. Diagnóstico da qualidade sanitária de plantas medicinais comercializadas no município de Currais Novos, RN. HOLOS. 2010;2:71-9, doi: 10.15628/holos.2010.370. 
5. Veiga Junior VF, Pinto AC, Maciel MAM. Plantas medicinais: Cura segura? Quím Nova. 2005 May;28(3):519-528, doi: 10.1590/S0100-40422005000300026.

6. Ribeiro MG, Costa EO, Leite DS, Langoni H, Garino Júnior F, Victória C, Listoni FJP. Fatores de virulência em linhagens de Escherichia coli isoladas de mastite bovina. Arq Bras Med Vet Zootec. 2006;58(5):724-31, doi: 10.1590/S0102-09352006000500004.

7. Silva N, Junqueira VCA, Silveira NFA, Taniwaki MH, Santos RFS, Gomes RAR. Manual de Métodos de Análise Microbiológica de Alimentos e Água. $4^{\mathrm{a}}$ ed., São Paulo: Livraria Varela, 2010. 535 p.

8. Cardoso ALSP, Tessari ENC, Castro AGM, Kanashiro AMI, Gama NMSQ. Pesquisa de coliformes totais e coliformes fecais analisados em ovos comerciais no laboratório de patologia avícola de descalvado. Arq Inst Biol. $2001 \mathrm{Jan}$;68(1):19-22.

9. Iaria ST, Furlanetto SMP, Campos MLC. Pesquisa de Staphylococcus aureus enterotoxigênico nas fossas nasais de manipuladores de alimentos em hospitais, São Paulo, 1976. Rev Saúde Pública. 1980;14(1):93100, doi: 10.1590/S0034-89101980000100008.

10. Raddi MSG, Leite CQF, Mendonça CP. Staphylococcus aureus: portadores entre manipuladores de alimentos. Rev saúde públ. 1988. 22:36-40, doi: 10.1590/S0034-89101988000100005.

11. Gomes EC, Negrelle RRB, Elpo ERS. Determinação da qualidade microbiológica e físico-química de chás de Cymbopogoncitratus (DC) Stapf (capim-limão). Acta Sci. 2008;30(1):47-54.

12. Freire FCO, Vieira IGP, Guedes MIF, Mendes FNP. Micotoxinas: importância na alimentação e na saúde humana e animal. Fortaleza, CE: Embrapa Agroindustrial Tropical, 2007, 48 p.

13. Maziero MT, Bersot LS. Micotoxinas em alimentos produzidos no Brasil. Rev Bras Prod Agroind. 2010;12(1):89-99.

14. Oliveira AL, Padilha CD, Ortega GG, Petrovick PR. Achyrocline satureioides (LAM.) DC (marcela), Asteraceae, Avaliação comparativa da droga vegetal e estudos preliminares de otimização da extração. Cad Farm. 2001 Jan;17(1):33-8.

15. Lorenzi H, Matos FJA. Plantas Medicinais no Brasil: Nativas e Exóticas. $2^{\mathrm{a}}$ ed. Nova Odessa, SP: Instituto Plantarum, 2008. $576 \mathrm{p}$.

16. RIO GRANDE DO SUL. Lei ${ }^{\circ} 11.858$, de 5 de dezembro de 2002. Institui a Marcela Planta Medicinal Símbolo do Estado do Rio Grande do Sul e dá outras providências. Palácio Piratini, Porto Alegre. Disponível em: http://clarimfarrapo.com. Acesso em: 13 nov. 2017.

17. Ikuta ARY, Barros IBI. Influência da temperatura e da luz sobre a germinação de marcela (Achyrocline satureioides). Pesq Agrop Bras. 1996 Dez;31(12):859-62.

18. Teixeira HF, Bassani VL. Avaliação da influência de adjuvantes farmacêuticos sobre características físicas, químicas, tecnológicas e farmacológicas de extratos secos nebulizados de Achyrocline satureioides (Lam.) DC.-Compositae-Marcela. Cad Farm. 1997;13(2):151-2.

19. Furlaneto L, Mendes S. Análise microbiológica de especiarias comercializadas em feira livre e em hipermercados. Alim. Nutri. Araraquara. 2004. 15(2):87-91.

20. Brito CS, Rossi DA. Bolores e leveduras, coliformes totais e fecais em sucos de laranja in natura e industrializados não pasteurizados comercializados na cidade de Uberlândia - MG. Biosci J. 2005 Jan;21(1):133-40.

21. Salvador FC, Graciolli ADN, Burin AS, Faila N. Análise microbiológica e de impurezas encontradas na Pimpinellaanisum L., comercializadas em lojas de produtos naturais de Apucarana - PR e região. Rev Saúde Pesqui. 2011 May;4(2):140-146.

22. Loguercio AP, Aleixo JAG. Microbiologia de queijo tipo minas frescal produzido artesanalmente. Cienc Rural. 2001;31(6):1063-7, doi: 10.1590/S0103-84782001000600024.

23. Sousa CP. Segurança alimentar e doenças veiculadas por alimentos: utilização do grupo coliforme como um dos indicadores de qualidade de alimentos. Rev APS. 2006 Jan;9(1):83-8.

24. Schaechter M, Engleberg NC, Eisenstein BI, Medoff G. Microbiologia: Mecanismos das doenças infecciosas. $3^{\mathrm{a}}$ ed. Rio de Janeiro: Guanabara Koogan S. A, 2002. 644 p.

25. Oliveira DCR, Soares EKB. Elaboração e caracterização físico-química, microbiológica e sensorial de produtos desidratados obtidos a partir de matérias-primas amplamente consumidas na Amazônia. Sci Plena. 2012;8(5).

26. Mota FM. Atividade antibacteriana in vitro de inflorescências de Achyrocline satureioides (Lam.) DC. Asteraceae - ("macela", "marcela") como fator de proteção em zoonoses [dissertação]. Porto Alegre (RS): Universidade Federal do Rio Grande do Sul, Porto Alegre. 2008. 91 p.

27. BRASIL. Farmacopeia Brasileira, v.1. Agência Nacional de Vigilância Sanitária. Brasília: ANVISA, 2010. Disponível em: http://portal.anvisa.gov.br/. Acesso em: 03 dez. 2017.

28. Borges MF, Nassu RT, Pereira JL, Andrade APC, Kuaye AY. Perfil de contaminação por Staphylococcus e suas enterotoxinas e monitorização das condições de higiene em uma linha de produção de queijo de coalho. Ciênc Rural. 2008 Ago;38(5):1431-8, doi: 10.1590/S0103-84782008000500037. 
29. Bernardi ACC, Pizzolitto EL, Pizzolitto AC. Detecção da produção de slime por estafilococos coagulasenegativa isolados de cateter venoso central. Rev Ciênc Farm Básica Apli. 2007;28(1):57-66.

30. López PG, Broussalis AM, Rodríguez MG, Coussio JD, Ferraro GE. Análisis de muestrascomerciales de "marcela" (Achyrocline satureioides). Acta Farmac Bonaerense. 1996;15(4):243-9.

31. Vasconcellos CMC. Extração supercrítica dos óleos voláteis de Achyrocline satureioides (Macela) e Vetiveria zizanioides (Vetiver): determinação da cinética de extração e estimativa de custos de manufatura [dissertação]. Campinas (SP): Universidade Estadual de Campinas, Campinas. 2007. 114 p.

32. Holzschuh MH. Estudo da estabilidade de produtos secos obtidos a partir de Achyrocline satureioides (Lam.) DC Asteraceae [tese]. Porto Alegre (RS): Universidade Federal do Rio Grande do Sul. 2008. 196 p.

33. Golçalves JM. Avaliação da atividade antimicrobiana e triagem fitoquímica dos extratos de espécies da família Asteraceae encontradas no semi-árido baiano [dissertação]. Feira de Santana (BA): Universidade Estadual de Feira de Santana; 2010. 91 p.

34. Verdi S, Younes S, Bertol CD. Avaliação da qualidade microbiológica de cápsulas e chás de plantas utilizadas na assistência ao tratamento da obesidade. Rev Bras Pl Med. 2013;15(4):494-502, doi: 10.1590/S1516-05722013000400004.

35. Souza FF, Maciel CCS. Produtos fitoterápicos e a necessidade de um controle de qualidade microbiológico. Rev Eletr Ciênc. 2010 Jul;3(2):22-30. 